\title{
O‘ZBEK TILIDAGI TILSHUNOSLIK TERMINLARINING MOBIL ILOVASINI YARATISH
}

\section{Farmonova Barno Davronovna \\ bfarmonova99@gmail.com}

\section{O‘zbekiston, Toshkent, ToshDO‘TAU “Kompyuter lingvistikasi” mutaxasisligi magistranti}

Annotatsiya. Mazkur maqolada o'zbek tilidagi tilshunoslik terminlari mobil ilovasini yaratish to ${ }^{6} g^{6}$ risida so $^{\prime} \mathrm{z}$ yuritiladi. O'zbek tilidagi tilshunoslik terminlarining mobil ilovasini yaratish va ularni keng ommaga tadbiq qilish uchun yaratilgan hisoblanadi. Ushbu maqolaning asosiy maqsadi tilshunoslik terminlari haqida umumiy ma'lumotlar va yetarlicha tushunchalar berib borildi.

Kalit so'zlar: tilshunoslik, terminologiya, kompyuter leksikografiyasi, an'anaviy tilshunoslik, izohli lug 'at.

Kirish. Til jamiyat tarixidan darak beruvchi buyuk vosita bo'lib, insonning ma'naviy va ma'rifiy shakllanishi va rivojlanishi uchun zarurdir. Til, inson va jamiyat bir-birisiz bo'lmaydi. Til inson tafakkuri, ruhiyati, madaniyati, urf-odati va shaxsiy xususiyatlari bilan bog'liqdir. Tilshunoslik fani umumiy va xususiy bo'lishi mumkin. Umumiy tilshunoslik jahon tillaridagi fonetik, fonologik, grammatik (morfologik va sintaktik), leksiksemantik, stilistik jihatlarini ilmiy o'rganadi. Bu alomatlaming aniq bir tildagi izohini xususiy tilshunoslik o'rganadi (masalan, o'zbek tili, yoki boshqa tillardagi izohi). Bu "tilshunoslik fanining alifbosi” turli tillari amaliy o "rganuvchi va ilmiy tadqiq etuvchilar uchun zarurdir.

Tilshunoslik fanining mavzusi tildir. Tilni har tomonlama chuqur o'rganish nazariy va amaliy ahamiyatga egadir. Shu sababli tilshunoslikni faqat nazariy fan deb emas, balki tadbiqiy (ingliz. Applied) va amaliyot uchun kerakli, ya'ni insonlar muloqoti uchun zamin fan sifatida qaramoq darkor. Tilshunoslik fanining asosiy vazifalari quyidagilardir:

— tilning yozuvi va imlo qoidalarini ishlab chiqishning nazariy va amaliy asoslarini ko'rsatib berish;

— tilning talaffuz meyorlarini belgilashning nazariy va amaliy asoslarini ishlab chiqish;

- tilning fonetika va fonologiyasi, morfologiya va sintaksisi, leksika va semantikasi (so'zlaming yasalishi va ma'nolari), stilistikasini o'rganish asoslarini belgilab berish; 
- til va jamiyat, til va tafakkur, til va madaniyat, til va psixologiya va semiotika (ramziy belgilami o'rganuvchi fan, lotincha semi — Gejiru, Hiuopa tikos — fan) kabi tilga bog'liq masalalami tadqiq

— tarixiy yozma manbalami ilmiy o'rganish asoslarini ishlab chiqish;

- eng qadimiy, ("bobo til") va uning boshqa tillar va shevalaiga munosabatini o'rganish; - uning hozirgi (uni "sinxroniya" deyiladi) holati bilan tarixiy rivojlanish bosqichlarini (uni "diaxroniya" deyiladi) ilmiy tadqiqot qilish;

— qadimiy yozuvlami o'rganish yo'li bilan eng qadimiy. Ulani tiklash yoki ulardagi turli alomatlami aniqlash. Yuqoridagilardan ko'rinadiki, tilshunoslik fani avvalo nazariy va ikkinchi navbatda tadbiqiy - amaliy fandir. Bu fanning aniq chegarasi yo'q, u ko'p qamrovli, ko'p qirrali va har tomonlama boshqa fanlar va ulaming sohalari bilan bog'liq bo'lgan fandir. Tilning o'zi esa juda murakkab ijtimoiy hodisa bo'lib, u belgilar tizimi sifatida insonlaming muloqot vositasi bo'lib xizmat qiladi. Bu o'rinda va nutqni farqlash zamin bo'ladi. Nutq - bu tilning va undagi belgilaming barcha qo'llanish holatlarini qamrab oladi. Yozma shaklda o'qib berish uchun tayyorlangan roman, qissa, hikoya va h.k. nutqqa tegishlidir. Lekin ulardagi, ya'ni nutqda doimiy qo'llanuvchi va ustuvor bo'lib qolgan jamiyat a'zolari tomonidan e'tirof etib qabul qilingan nutqdagi unsurlar majmui til deb yuritadi. TU — jamiyatimiz a'zolarining buyuk vositasi bo'lsa, nutq — bu vositaning qo'llanishidir. Yozilgan yoki aytilgan nutqning bo'lagi matn deb yuritadi. Yozma nutq va og'zaki nutq farqlanganidek, yozma matn va og'zaki (monolog, dialog kabi) matn ham farqlanadi. TUdagi jamiyat a'zolari tomonidan qabul qilingan ustuvor bo'lgan xususiyatlar davr o'tishi bilan turli o'zgarishlarga duchor bo'lishi mumkin. TUdagi o'zgarishlar va tilning rivojlanishi murakkab muammolami keltirib chiqaradi. Tildagi muammo va masalalami sinxroniya va diaxroniyada (ya'ni hozirgi va tarixiy holati) ilmiy tadqiq etish zarur.

Tilshonoslik yoki lingvistika tillarni o'rganuvchi fandir. Tilshunoslikning amaliy va nazariy turlari mavjud bo'lib, nazariy tilshunoslik tilning strukturasi (grammatikasi) va uning ma'nosi (semantikasini) o'rganadi. Grammatika morfologiya (so'zlarning tuzilishi va o'zgarishi), sintaksis (so'zlarning iboralarga va gaplarga biriktrilish qoidalari) va fonologiya (tilni abstrakt tovushlar yordamida o'rganish) fanlarini qamrab oladi. Amaliy tilshunoslik, asosan, tilshunoslikda o'rganilgan nazariy bilimlarni amaliyotda qo'llash bilan shug'ullanadi. Amaliy tilshunoslik tarkibiga xorijiy tillarni o'rganish va o'rgatish, tarjima, nutq terapiyasi va nutq patalogiyasi kabi fanlar kiradi.

Tilshunoslik, lingvistika — til haqidagi, uning ijtimoiy tabiati, vazifasi, ichki 
tuzilishi, tasnifi, muayyan tillarning amal qilish (faoliyat) qonunlari, tarixiy taraqqiyoti haqidagi fan. Maqsadi, vazifasi va shu kabiga ko'ra, T.ning bir necha yo'nalishlari (sohalari) bor: umumiy T. - tilni umuman insonga xos hodisa sifatida o'rganuvchi, asosiy vazifasi dunyo tillariga xos eng umumiy belgixususiyatlarni aniqlash va yoritish bo'lgan soha, xususiy T. - ayrim bir til belgixususiyatlarini o'rganuvchi soha; amaliy T. - tildan foydalanish bilan aloqador amaliy masalalarni (eksperimental fonetika, leksikografiya, lingvostatistika, transkripsiya, transliteratsiya va boshqalar) hal qilish metodlarini ishlab chiquvchi yo'nalish; matematik lingvistika, strukturaviy tilshunoslik, kiyo'siytarixiy tilshunoslik va boshqa Paralingvistika, etnolingvistika, psixolingvistika, sotsiolingvistika kabi sohalar so 'zlovchi (shaxs)ning jamiyatdagi faoliyati bilan aloqador til xususiyatlarini o'rganadi.

Mazkur yo"nalishlardan tashqari T.ning har bir tildagi muayyan sathlar va birliklarni o'rganuvchi ko'plab tarmoq va bo'limlari bor: semasiologiya til birliklari ma'nolarini o'rganadi [3]; fonetika va fonologiya tilning tovush qurilishini tekshiradi; leksikologiya va frazeologiya tilning lug'aviy materialini tadqiq etadi. So'z yasalishining tadqiqot ob'yekti so'zlarning yasalish usullari va ushbu usullarning mahsuldorligi bo'lsa, grammatika (morfologiya va sintaksis) so'z o'zgarishlarini va so'zlarning gaplar va so $^{6} z$ birikmalari sifatida birikishi qonuniyatlarini o'rganadi. Tilning har bir bo'limida yanada kichikroq (maydaroq) maxsus bo'limchalar bo'lishi mumkin. Mac, leksikologiya doirasida onomastika bo'limchasi bo'lib, u, o'z navbatida, antroponimika, toponimika va boshqalarga bo'linadi. Muayyan tilning hududiy farklanishi (differensiatsiyasi)ni dialektologiya o'rganadi. Mazkur bo'limlarning har birida tilning hozirgi ahvoli va uning tarixiy taraqqiyoti tadqiq etiladi (Diaxroniya, Sinxroniya). Jahon tillari, ularning oilalari va guruhlarini o'rganuvchi Til. tarmoklari: arabistika (arabhunoslik), germanshunoslik, turkiyshunoslik, slavyanshunoslik, finugorshunoslik va boshqa Tillarning o'zaro ta'sirlashuvi, yordamchi xalkaro tillarni yaratish nazariyasi va amaliyoti, shuningdek, bir tildan ikkinchi tilga tarjima qilish muammolarini interlingvistika va tarjima nazariyasi o'rganadi.

Til fan sifatida ona tili va xorijiy tillarni o'rganishda, terminologiyani ishlab chiqish va takomillashtirishda, lisoniy matnlarni ilmiy sharhlashda, mashina tarjimasida muhim ahamiyatga ega; mavjud va xayoliy narsalar (moddiylik va g'oyaviylik)ning o'zaro aloqadorligi muammolarini hal qilish, ijtimoiy ongni va ijtimoiy mavjudot bo'lmish insonning o'zini to' $\mathrm{g}^{6} \mathrm{ri}$ tushunish uchun nazariy xulosalar chiqarishga imkon berdi. Til va tafakkurning, lisoniy va mantiqiy birlik 
(kattalik)larning o'zaro aloqasi muammosi Til. va falsafa tomonidan baravar, bir vaqtning o'zida o'rganiladi. Asosiy lingvistik metodlar sifatida tavsifiy (qiyosiy, konfrontativ, kontrastiv, tipologik), tarixiy (qiyosiytarixiy, komparativ) va normativstilistik (me'yoriyuslubiy) metodlarni ko'rsatish mumkin. Tilda yana maxsus tadqiqot usullari - lisoniy hodisalarni kuzatish, lisoniy eksperiment, lingvistik modellashtirish, lingvistik talqin usullari ham mavjud. Til, falsafa va filol. fanlari tutashgan chegarada paydo bo'lgan.

M.V.Lomonosovning "Rus fammatikasi" asarida rus adabiy tilining fonetik, morfologik, qisman sintaktik xususiyatlari birinchi marta izchil bayon qilindi.

Uyg'onish davrida antik dunyo madaniy merosiga bo'lgan qiziqish klassik filologiyaning rivojlanishiga ham turtki bo'ldi. Shu bilan bir qatorda, yangi, zamonaviy yevropa tillarini mantiqiy asosda o'rganish boshlandi. Qiyosiy metodika va tarixiylik tamoyilining qo'llanishi qiyosiytarixiy T.ka asos soldiki, bu soha tillarning qarindoshligini o'rganishda, tillarning genealogii: tasnifshsh ishlab chiqishda, qarindosh tillarning, tillar oilalarining, asosan, hindevropa tillari oilasining tarixiy taraqqiyotini o'rganishda, tillarning qad. holatini qayta tiklashda va boshqalarda muvaffaqiyatlarga erishdi. T.dagi qiyosiytarixiy yo'nalishning rivojlanishiga nemis olimlari F. Bopp, Ya. Grimm, A. F. Pott, A. Shleyxer, A. Dits, daniyalik R. K. Rask, chexiyalik Y. Dobrovskiy, avstriyalik F. Mikloshich, rus olimi A. X. Vostokov va boshqa katta hissa qo'shdilar. Umumiy T. asoslari, tilni "faoliyat" va "faoliyat mahsuli" sifatida tushunish, tilning tashqi va ichki shakli haqidagi ta'limot, tillarning tipologii tasnifi va boshqa muammolar nemis olimi V. Gumboldt tomonidan ishlab chiqildi. Uning fikrlari XIX-XX asrlar g'arb T.ning bir qancha yo'nalishlari rivojiga katta ta'sir ko'rsatdi. Gumboldt T. mantiqiylikdan qutulishi va $\mathrm{O}^{6} \mathrm{z}$ metodiga ega bo'lishi kerakligini, tilning tizim xususiyatiga egaligini, uning 2 jildi - tovush va ma'nosi borligini qamda ijtimoiy hodisaligini asosli bayon qildi. XIX asr o'rtalarida A. Shleyxer T.da biologik nazariyalarni qo'llashga urinib ko'rdi.

Lingvistik naturalizmni tanqid qilish negizida yosh grammatikachilar (nemis olimlari A. Leskin, K. Brugman, G. Ostxof, B. Delbryuk, G. Paul va boshqalar) maktabi shakllanib, u asosiy e'tiborni jonli tillarni o'rganishga karatdi. Ushbu maktab vakillari qiyosiytarixiy T.ning rivojini yangi bosqichga olib chiqdilar. 19asrda hindevropashunoslikning asosiy tarmoqlari (ellinistikayunonshunoslik, romanistika, germanistika, slavyanshunoslik, keltshunoslik va boshqalar) batamom shakllanib bo'ldi. Hindevropa tillari uchun ishlab chiqilgan qiyosiytarixiy metod tamoyillari ushbu oilaga kirmaydigan boshka tillarga ham tadbiq etildi. Shu tariqa 
semitologiya, turkiyshunoslik, finugorshunoslik, afrikashunoslik kabi sohalar shakllanadi. Tilning 20-asr boshlaridagi rivojlanishida Ferdinand de Sossyurnnnt asarlari, birinchi navbatda, "Umumiy tilshunoslik kursi" (1916) muhim rol o ynadi. Sossyur tilning belgi nazariyasini yaratdi, sinxroniya va diaxroniya, ichki lingvistika, tashki lingvistika va boshqa muammolarni tadqiq qildi. F. de Sossyur g'oyalari keyinroq paydo bo'lgan lingvistik strukturalizm maktablarida: Praga lingvistik maktabi - funksional tilshunoslik, Kopengagen lingvistik to'garagi (glossematika), Jeneva maktabi, Amerika deskriptiv (tavsifiy) T.da yanada rivojlantiriladi.

Struktural oqimlar bilan bir qatorda boshqacha yo"nalishlar va qarashlar rivojlana boshladi: psixologik yo"nalish (nemis olimlari X. Shteyntal va V. Vundt asarlari; rus olimi V. V. Potebilanya ham ushbu yo'nalishga qo'shiladi), neyrolingvistika va boshqa Materialistik dunyoqarashning keng yoyilishi bilan eksperimental fonetika va lingvistik geografiya xam rivojlana boshladi. Keyinchalik tilda yangi yo'nalish va bo'limlar: psixolingvistika, sotsiolingvistika, etnolingvistika, semiotik lingvistika, transformatsiyey lingvistika, matn lingvistikasi va boshqa paydo bo 'ladi. Hozirgi xorijiy tilda materialistik nazariyalar bilan bir qatorda idealistik tamoyillarga asoslangan nazariyalar.

Xulosa. Tadqiqot natijalarining ilmiy ahamiyati o'zbek tili tilshunoslik, terminologiya, annanaviy tilshunoslik bo 'yicha nazariy manba yaratishda, darslik hamda qo'llanmalarni takomillashtirishda, maxsus kurslar uchun qo'shimcha materiallar berishda, o'zbek tilidagi tilshunoslik terminlarini foydalanilishi bilan izohlanadi. Yuqoridagilardan ko'rinadiki, tilshunoslik fani avvalo nazariy va ikkinchi navbatda tadbiqiy - amaliy fandir. Bu fanning aniq chegarasi yo' $\mathrm{q}, \mathrm{u}$ ko'p qamrovli, ko'p qirrali va har tomonlama boshqa fanlar va ularning sohalari bilan bog'liq bo'lgan fandir.

\section{Foydalanilgan adabiyotlar}

1. Acxiom Corporation (2011). Experiences verifying the identity of online students. Acxiom Corporation. Al-Alone, K. I. (2015). Learning Effects of Using Learning Management System (Moodle) by Students of Arab Open University. pp.15-40.

2. Xolmanova Z.T. Tilshunoslikka kirish. - Toshkent, 2007. - 177 b.

3. Акшина А.А. Пособие по курсу «Введение в язикознание» М.,1969.

4. Карпова, О. М. Словари издательства HarperCollins: находки и решения/ О. М. Карпова // Language and Communication - Issue I. Rostovon 
Don, 2001. - $57 \mathrm{c}$.

5. Hojiyev A. Tilshunoslik terminlarining izohli lug'ati.

6. Proceedings of MAC-ETel 2015. Multidisciplinary Academic Conference on Education, Teaching and E-Learning, Prague. Al-Amleh, M. (2014). Identifying the Palestinian Culture According To Hofstede's Theory. MA thesis, Jerusalem, occupied Palestinian Territories: Al-Quds University. Alkailani, M., Azzam, I. A., \& Athamneh, A. B. (2012). Replicating Hofstede in Jordan: ungeneralized, reevaluating the Jordanian culture. International Business Research, 5 (4), p.71.

7. Mahkamov N., Ermatov I. Tilshunoslik terminlarining izohli lug'ati. Toshkent - 2013yil

8. American University in Cairo News (2015) Faculty Reform Requires Change in the Mindset of Educators, Youth [Online], Cairo. Available at:http://www.aucegypt.edu/news/stories/faculty-reform-requireschange-mindseteducators-youth (Accessed 27/11/2017) Assad, R., Salehi-Isfahani, D., \& Hendy, R. (2014). Inequality of opportunity in educational attainment in Middle East and North Africa: evidence from household surveys. In Economic Research Forum Working Paper Series No (Vol. 834). 